\title{
Sol-Jel Yöntemiyle Hazırlanan TiO2 Filmlerin Optik ve Elektrokromik Özellikleri
}

\author{
Hasan SARIGÜL, İdris SORAR* \\ Mustafa Kemal Üniversitesi, Fen Edebiyat Fakültesi, Fizik Bölümü, 31034, Antakya - Hatay
}

\begin{abstract}
ÖZ
Bu çalışmada sol-jel kaplama yöntemi kullanılarak Corning cam ve ITO altlıklar üstüne titanyum dioksit (TiO $)_{2}$ fillmleri kaplanmıştır. Kaplama işlemi için oluşturulan çözelti uygun miktarda titanyum (IV) n-bütoksit, asetik asit ve etanol içermektedir. Filmlerin taşıııılar üstüne kaplanmasında 2000 devir/dakika hızında döndürerek kaplama yöntemi kullanılmıştır. Filmler çeşitli sıcaklıklarda 1sıl işleme tabi tutulmuş ve analiz edilmişlerdir. Filmlerin yapısal analizi X-ışınları kırınımı kullanılarak yapılmıştır. 1, 3 ve 5 katlı olarak Corning cam üzerine hazırlanıp $120^{\circ} \mathrm{C}$ ve $500{ }^{\circ} \mathrm{C}$ ' de 1 sıl işleme tabi tutulan $\mathrm{TiO}_{2}$ filmlerin amorf yapıda olduğu belirlenmiştir. Amorf TiO filmlerin yasak enerji aralığının 3,78 eV ile 4,04 eV arasında değiştiği hesaplanmıştır. Diğer taraftan 7 katlı olarak hazırlanan ve $500{ }^{\circ} \mathrm{C}$ ' de 1 sıl işleme tabi tutulan filmin ise anataz kristal yapısında olduğu bulunmuştur. Bu filmlerin yasak enerji aralığ $3,82 \mathrm{eV}$ olarak bulunmuştur. Optik ölçümlerde filmlerin yüksek geçirgenliğe sahip olduğu görülmüştür. Elektrokimyasal ölçümler için $1 \mathrm{M} \mathrm{KOH}$ elektroliti, karşıt elektrot olarak platin tel, referans elektrot olarak $\mathrm{Ag} / \mathrm{AgCl}$ elektrot ve çalışma elektrotu olarak kaplanan $\mathrm{TiO}_{2}$ fillmler kullanılmıştır. Filmler katodik elektrokromik renklenme göstermiştir.
\end{abstract}

Anahtar kelimeler: $\mathrm{TiO}_{2}$, sol-jel, elektrokromik özellikler, optik özellikler

\section{Optical and Electrochromic Properties of TiO2 Films Prepared by Sol Gel}

\section{Method}

\begin{abstract}
In this study thin films of titanium dioxide $\left(\mathrm{TiO}_{2}\right)$ were prepared on Corning glass and ITO substrates by sol-gel method. The solution prepared for coating have an amount of mixture of titanium (IV) n-butoxide, acetic acid and ethanol. Preparation of the films on the substrates was made by spin coating method at $2000 \mathrm{rpm}$. Following a heat treatment at various temperatures, films were characterized. The structural analyses of the films were done through X-ray diffraction. 1, 3 and 5 layers of $\mathrm{TiO}_{2}$ films prepared on Corning glass and annealed at $120^{\circ} \mathrm{C}$ and $500{ }^{\circ} \mathrm{C}$ were found to be amorphous. Band gap of amorphous $\mathrm{TiO}_{2}$ films changes between $3.78 \mathrm{eV}$ and $4.04 \mathrm{eV}$. However, 7 layer-prepared film annealed at $500^{\circ} \mathrm{C}$ was found to be crystalline anatase phase. Band gap of the crystalline films was found to be $3.82 \mathrm{eV}$. Optical measurement showed that films have high transparency. Electrochemical measurements were made by using $\mathrm{Ag} / \mathrm{AgCl}$ as reference electrode, platinum wire as counter electrode and $\mathrm{TiO}_{2}$ as working electrode in $1 \mathrm{M} \mathrm{KOH}$ solution. Films showed cathodic electrochromic coloration.
\end{abstract}

Keywords: $\mathrm{TiO}_{2}$, sol-gel, electrochromic properties, optical properties

\section{GÍRIŞ}

Elektrokromik malzemeler, elektrik alan uygulandığında optik özelliklerini tersinir olarak değiştirmektedirler [1, 2]. Modern cihazların geliştirilebilmesi ve enerji verimliliği sağlamalarından dolayı elektrokromik malzemeler ilgi çekmektedir. Elektrokromik malzemeler hâlihazırda arabalarda [3], binalarda [4], yolcu uçaklarında [5], uzay araçlarında ve güneş gözlüklerinde [6] kullanılmaktadırlar.

Geçiş metallerinin oksitleri ince film formunda elektrokromik özellik göstermektedirler. Geçiş metallerinin oksitleri arasında olan titanyum dioksit $\left(\mathrm{TiO}_{2}\right)$ 'in ince filmlerinin hazırlanması ve karakterizasyonu, elektrokromik malzemeler arasında popüler bir araştırma konusudur [7-9]. $\mathrm{TiO}_{2}$ ince filmler yüksek kırma indisine ve yüksek yasak 
enerji aralığına sahiptir. Dalgaboyu dağılımının büyük kısmında yüksek geçirgenlik gösterir [10]. $\mathrm{TiO}_{2}$ ince filmler anataz, brokit ve rutil olmak üzere üç farklı kristal yapıda bulunur [11]. $\mathrm{TiO}_{2}$, ince film olarak elektrokromik devre elemanı [12], termokromik devre elemanı, elektrokromik film, yansitmayan kaplama veya yüksek yansitmalı kaplama olarak [13-15], saydam iletkenler [16] ve güneş pilleri $[17,18]$ gibi alanlarda yaygın bir şekilde kullanılmakta olup farklı optik özelliklerinden dolayı değişik çalışma alanlarında da yer bulmaktadır [19].

$\mathrm{TiO}_{2}$ ince filmler hazırlanırken RF saçtırma [20], ultrasonik sprey piroliz [21], kimyasal buhar depolama [22], darbeli lazer biriktirme [23], DC magnetron [24], sol-jel [25,26] gibi birçok ince film kaplama yöntemi kullanılmaktadır. $\mathrm{Bu}$ yöntemlerden biri olan sol-jel yöntemi, homojen yapı elde edilmesi, her aşamanın kontrol altında tutulabilmesi, basit cihazlar gerektirmesi ve düşük sıcaklıklarda uygulanabilir olması sebebiyle metal oksit kaplamalar hazırlamak için kullanışlı bir yöntemdir [27].

$\mathrm{TiO}_{2}$ ince filmlerin optik, yapısal ve elektronik özellikleri üzerine birçok çalışma vardır. Yapılan çalışmalarda, sol-jel yöntemiyle hazırlanan $\mathrm{TiO}_{2}$ filmlerin $500{ }^{\circ} \mathrm{C}$ ' de tavlama sonrası anataz yapı gösterdiği rapor edilmiştir [26]. Niu W. ve arkadaşlarının yaptığı bir çalışmada ise, sol-jel yardımıyla hazırlanmış amorf yapılı $\mathrm{TiO}_{2}$ ince filmlerin kristal yapıda olanlara [28]. Hosseini A. ve arkadaşları yaptıkları çalışmada, sol-jel döndürerek kaplama yöntemi kullanarak ITO ve cam taşıyıcılar üzerine $\mathrm{TiO}_{2}$ filmler üretip, tavlama sonrasında cam taşıııcı üzerine hazırlanan filmlerin amorf yapıl1, ITO üzerine kaplanan filmlerin ise anataz yapıda olduğunu belirtmişlerdir [29]. Bu çalışmada farklı katman sayılarına sahip $\mathrm{TiO}_{2}$ ince filmler sol-jel yöntemiyle hazırlanmıştır. Optik ve yapısal özellikler için, cam üzerine hazırlanan ve $500{ }^{\circ} \mathrm{C}$ de tavlanan filmler kullanılmış, elektrokromik ölçümler için ise ITO üzerine hazırlanan filmler kullanılmıştır. $\mathrm{TiO}_{2}$ 'in elektrokromik özellikleri üzerine yapılan çalışmalarda, $\mathrm{KOH}$ elektroliti kullanılarak filmin içerisine $\mathrm{H}^{+}$iyonunun sokulup çıkarılmasıyla ilgili çalışmalar kısıtlı olduğundan, bu çalışmada $\mathrm{H}^{+}$iyon girişçıkışları ile filmler elektrokromik olarak karakterize edilmiştir.

\section{MATERYAL VE YÖNTEM}

$\mathrm{Bu}$ çalışmada sol-jel döndürerek kaplama yöntemi kullanarak $\mathrm{TiO}_{2}$ ince filmler Corning ve ITO taşıyıcılar üzerine kaplanmıştır. Optik ölçümler için Corning 2947 taşıyıc1; elektrokromik ölçümler için ise, iletken yüzeye sahip ITO kaplanmış cam taşıyıcı kullanılmıştır. ITO taşıyıcıların iletken yüzeyinin bir kenarına ısıya dayanıklı bant yapıştırılarak maskeleme yapılmıştır.

Çözelti hazırlamak için başlangıç malzemeleri olarak titanyum (IV) bütoksit, asetik asit ve etanol kullanılmıştır. Hacimce 20:1 (etanolün titanyum (IV) bütoksit miktarına hacimce oranı) oranında titanyum (IV) bütoksit çözeltisi için öncelikle $50 \mathrm{~mL}$ etanolun $15 \mathrm{~mL}$ 'si behere alınır. Daha sonra $0,5 \mathrm{~mL}$ asetik asit behere yavaşça damlatılarak manyetik karıştırıcıda 10 dakika karıştırılır. Daha sonra, geriye kalan $35 \mathrm{ml}$ etanol bu çözeltinin üstüne eklenir. Karıştırılmakta olan etanol-asetik asit çözeltisinin içine 2,5 mL titanyum (IV) bütoksit yavaşça eklenerek 1 saat boyunca oda sıcaklığında karıştırılmaya devam edilir. 1 saat karıştırma sonunda şeffaf ve berrak bir çözelti elde edilir [27].

Elde edilen çözelti kullanılarak 2000 devir/dakika döndürme hızında taşıyıc üzerine filmler oluşturulmuştur. Kaplanan filmler $100^{\circ} \mathrm{C}^{\prime} \mathrm{de} 5$ dakika boyunca kurutulmuştur. Eğer 1 kattan fazla film kaplanacak ise kurutma işleminden sonra filmlerin oda sıcaklığına düşmesi beklenip her kat için bu süreç tekrar edilmiştir. En son kurutma işlemi için filmler $120{ }^{\circ} \mathrm{C}$ ' de 1 saat 1 sıl işleme tabi tutulmuştur. Asetik asidin $118^{\circ} \mathrm{C}^{\prime}$ de ve etanolün $78{ }^{\circ} \mathrm{C}$ ' de buharlaşmasından dolayı bu sıcaklık değeri seçilmiştir. Optik ölçümler için Corning taşıyıcı üzerine kaplanan filmler $120^{\circ} \mathrm{C}$ ' de ve $500{ }^{\circ} \mathrm{C}$ 'de 1 saat boyunca tavlanmıştır. Kristal yapının incelenmesi için ise Corning ve ITO taşıyıcılar üzerine kaplanan filmler firında $120^{\circ} \mathrm{C}$ 'de kurutulduktan sonra $500{ }^{\circ} \mathrm{C}$ 'de 1 saat boyunca tavlanmıştır. Elektrokromik ölçümler için amorf $\mathrm{TiO}_{2}$ filmlerin daha iyi sonuç verdiği bilindiğinden ITO üzerine kaplanan filmler sadece $120^{\circ} \mathrm{C}^{\prime}$ de kurutulmuştur. Tavlama ve kurutma işlemleri için Protherm 12/50/450 model tüp firın kullanılmıştır.

Hazirlanan filmler XRD, SEM ve UV-Vis spektrofotomotre ile analiz edilmiştir. Kaplanan filmlerin kristal yapılarının incelenmesi, Rigaku Smartlab X-1şını kırınım cihazı (XRD) ile yapılmıştır. Bu ölçümler $20^{\circ} \leq 2 \theta \leq 60^{\circ}$ tarama aralığında, $4 \%$ dakika tarama hızı ve $0,02^{\circ}{ }^{\circ}$ lik adımlarla 1,54 $\AA$ dalgaboylu $\mathrm{Cu}-\mathrm{K}_{\alpha}$ 1şını kullanılarak yapılmıştır. Film yüzeyinin yapısı, taramalı elektron mikroskobu (Scanning Electron Microscobe, SEM) ile incelenmiştir. Filmlerin geçirgenlik ve soğurma ölçümleri Thermo Evolution 160 cihazıyla 190-1100 nm dalgaboyu aralığında alınmıştır. Elektrokimyasal ölçümler Parstat 2337 galvanostat/ potentiostat ölçüm cihazıyla yapılmıştır. Elektrokimyasal ölçümler, $\mathrm{H}^{+}$iyonunun $\mathrm{TiO}_{2}$ ince filmlere sokulup çıkarılmasıyla yapılmıştır. Ölçümlerde $1 \mathrm{M}$ konsantrasyona 
sahip $\mathrm{KOH}$ elektroliti, karşıt elektrot olarak platin tel, referans elektrot olarak $1 \mathrm{M} \mathrm{Ag} / \mathrm{AgCl}$ elektrot ve çalışma elektrotu olarak kaplanan $\mathrm{TiO}_{2}$ filmler kullanılmıştır. Hazırlanan filmlerin kalınlıkları PARAV bilgisayar programıyla [30] hesaplanmıştır.

\section{BULGULAR VE TARTIŞMA}

\subsection{TiO2 Filmlerin Optiksel Özellikleri}

Farklı katman sayısına sahip $120^{\circ} \mathrm{C}$ 'de 1 saat kurutulmuş $\mathrm{TiO}_{2}$ filmlerin geçirgenlik eğrileri Şekil 1'de görülmektedir. 1 katlı filmlerin geçirgenliği ortalama \%82 civarındadır. 3 katlı filmlerde ise bir tepe ve bir çukur bölge oluştuğu görülmektedir. 3 katlı filmin maksimum geçirgenliği 540 nm dalgaboyunda olup, değeri \%89'dur. 5 katlı filmlerde iki tepe ve iki çukur oluşmuştur. Filmin maksimum geçirgenliği 484 nm'de \%88 olmuştur. Film ayrıca 824 nm'den daha büyük dalgaboyları için ortalama $\% 87$ civarında yüksek bir geçirgenlik göstermiştir. 7 katlı filmlerde üç tepe ve üç tane çukur bulunmaktadır. Filmin maksimum geçirgenliği 476 nm'de \% 88 olmuştur. Filmlerin katman sayısı artıkça eğrilerde çukur ve tepe noktalarının sayısının artığı gözlenmektedir. $\mathrm{Bu}$ da filmlerin kalınlıklarının arttığının göstergesidir. PARAV programıyla hesaplanan kalınlık değerleri 3,5 ve 7 katlı filmler için sirasiyla $188 \pm 6$, $262 \pm 10$ ve $367 \pm 17 \mathrm{~nm}$ 'dir.1 katlı filmlerde girişim deseni oluşmadığından film kalınlığı hesaplanamamıştır.

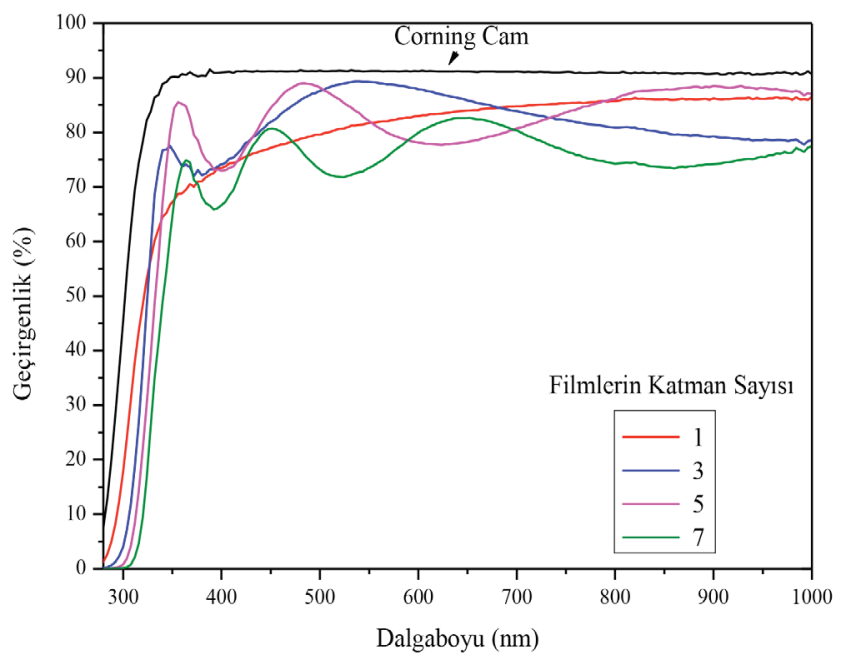

Şekil 1. $120^{\circ} \mathrm{C}^{\prime}$ de 1 saat kurutulmuş filmlerin geçirgenlik eğrileri

Filmlerin yasak enerji aralığı, filmlerin soğurma grafikleri ve Tauc yasası olarak bilinen Denklem 1 ile hesaplanmıştır [31]. $\alpha h v=\mathrm{A}\left(h v-\mathrm{E}_{\mathrm{g}}\right)^{\mathrm{m}}$

$\mathrm{Bu}$ denklemde yer alan $\alpha$, soğurma katsayısını; foton enerjisini; $\mathrm{E}_{\mathrm{g}}$, yasak enerji aralığını ifade eder. $\mathrm{m}$ üstel bir sabittir ve doğrudan geçişli malzemeler için $1 / 2$, dolaylı geçişli malzemeler için ise 2'dir. Kaynaklarda, $\mathrm{TiO}_{2}$ 'in doğrudan geçişli yarıiletken olduğu verilmektedir. Denklem 1'e göre $\left(h v-\mathrm{E}_{\mathrm{g}}\right)^{\frac{1}{2}}$ ifadesini sıfır yapan değer filmin yasak enerji aralığını vermektedir.

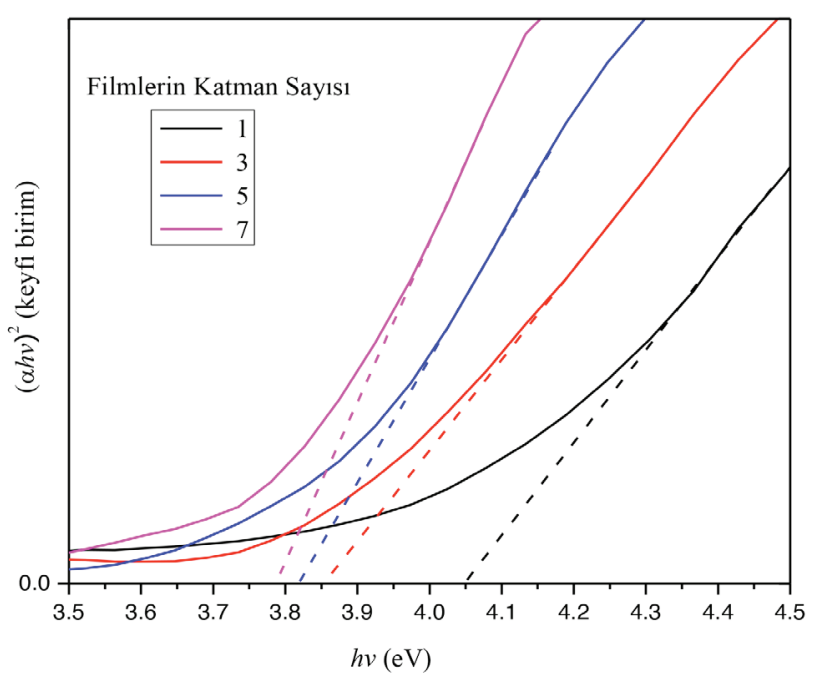

Şekil 2. $120^{\circ} \mathrm{C}$ 'de 1 saat kurutulmuş $\mathrm{TiO}_{2}$ filmlerin grafiği

Şekil 2'de $\mathrm{TiO}_{2}$ filmlerin soğurma verileri yardımıyla çizilmiş $(\alpha h v)^{2}-(h v)$ grafikleri yer almaktadır. Yüksek enerji bölgesindeki her bir lineer çizgiye paralel çizgiler çizilerek bu çizgilerin x eksenini kestiği nokta, yani yasak enerji aralığı, hesaplanmıştır. Tablo 1.'de farklı katman sayılarına sahip filmler için bulunan yasak enerji aralıkları verilmiştir. Elde edilen verilerden katman sayısı artıkça yasak enerji aralığının azaldığı görülmüştür. Yasak enerji aralığı en düşük olan film $3,78 \mathrm{eV}$ değerine sahip 7 katlı $\mathrm{TiO}_{2}$ 'dir.

Tablo $1.120^{\circ} \mathrm{C}$ 'de 1 saat kurutulmuş $\mathrm{TiO}_{2}$ filmlerin katman sayısına göre yasak enerji aralıkları.

\begin{tabular}{cc} 
Katman sayısı & $\begin{array}{c}\text { Yasak enerji aralı̆̆ } \\
(\mathbf{e V})( \pm 0,02)\end{array}$ \\
1 & 4,04 \\
3 & 3,85 \\
5 & 3,81 \\
7 & 3,78 \\
\hline
\end{tabular}


Cam taşıyıcı üstüne kaplanan filmler $120^{\circ} \mathrm{C}$ 'de 1 saatlik kurutma işleminden sonra tavlama işlemine tabi tutulmuştur. $1,3,5$ ve 7 katman olarak hazırlanan ve $120^{\circ} \mathrm{C}$ ve $500^{\circ} \mathrm{C}$ 'de tavlanan filmlerin XRD ölçümleri sonucunda sadece $500^{\circ} \mathrm{C}^{\prime}$ de 1 saat tavlanmış olan 7 katlı filmin kristal yapıda olduğu, diğerlerinin tamamının ise amorf yapıda olduğu gözlenmiştir. Şekil 3'de XRD grafiği verilen 7 katlı filmde (101), (103), (004), (112), (200), (105) ve (211) tepe düzlemleri gözlenmiştir. Bu değerler ile ICDD (International Centre for Difraction Data)'nin 01-075-2547 kart numaral1 $\mathrm{TiO}_{2}$ anataz yapısının uyumlu olduğu gözlenmiştir. Anataz yapıdaki bu filmin kristal boyutu, Denklem 2'deki Scherrer Formülü ile hesaplanmıştır:

$$
D=\frac{K \lambda}{\beta \operatorname{Cos} \theta}
$$

Burada $D$, kristal boyutunu; $K$, deneysel bir düzeltme katsayısını $(K=0,94) ; \lambda$, kullanılan $\mathrm{X}$-ışının dalgaboyunu $(1,54 \AA) ; \beta, \quad X-1 s ̧ ı n ı$ kırınım desenindeki tepenin yarı yüksekliğindeki tam genişliğinin radyan cinsinden değerini (full width at half maxima, FWHM); ve $\theta$ kırınım açısını göstermektedir. Şekil 3'de gösterilen XRD grafiğinden elde edilen veriler Tablo 2' de yer almaktadır. 7 katlı $\mathrm{TiO}_{2}$ filmin ortalama kristal boyutu yaklaşık olarak $17 \mathrm{~nm}$ bulunmuştur.

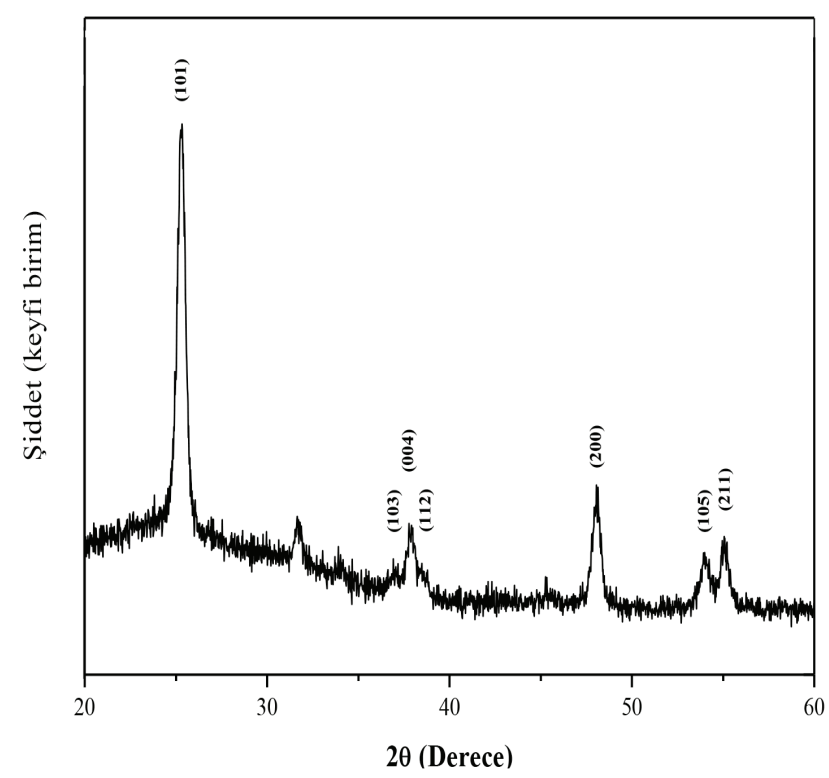

Şekil 3. Cam taşıyıcı üstüne kaplanmış ve $500^{\circ} \mathrm{C}^{\prime}$ de 1 saat tavlanmış 7 katlı $\mathrm{TiO}_{2}$ filmin XRD grafiği
Tablo 2. Cam üstüne kaplanan ve $500^{\circ} \mathrm{C}$ 'de 1 saat tavlanan 7 katlı $\mathrm{TiO}_{2}$ filmin XRD verileri

\begin{tabular}{cccc}
\hline $\begin{array}{c}\text { Miller } \\
\text { indisleri (hkl) }\end{array}$ & $\begin{array}{c}\text { Tepenin } \\
\text { olduğu açı, } \\
\text { 2ө (derece) }\end{array}$ & $\begin{array}{c}\text { FWHM } \\
\text { (derece) }\end{array}$ & $\begin{array}{c}\text { Kristal } \\
\text { boyutu } \\
\text { (nm) }\end{array}$ \\
\hline$(101)$ & 25,27 & 0,52 & 16,68 \\
$(004)$ & 37,52 & 0,45 & 19,48 \\
$(200)$ & 48,04 & 0,52 & 17,48 \\
$(211)$ & 55,07 & 0,58 & 16,14 \\
\hline
\end{tabular}

Anataz kristal yapısına sahip 7 katlı $\mathrm{TiO}_{2}$ filmin geçirgenlik ve $(\alpha h v)^{2}-(h v)$ grafikleri sırasıyla Şekil 4 ve Şekil 5'de gösterilmektedir.

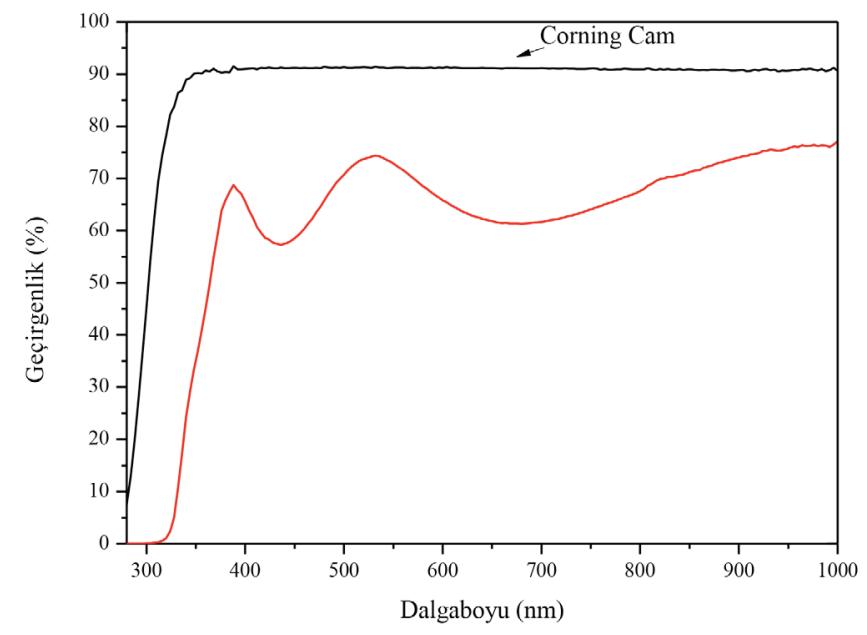

Şekil 4. $500^{\circ} \mathrm{C}^{\prime}$ de 1 saat tavlanan 7 katlı filmin geçirgenlik

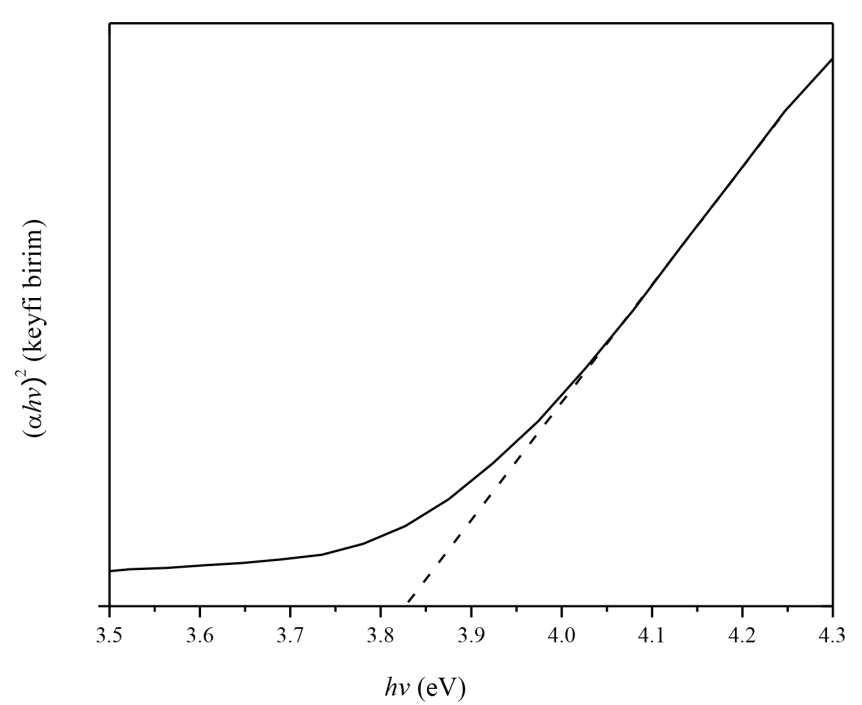

Şekil 5. $500^{\circ} \mathrm{C}^{\prime}$ de 1 saat tavlanan 7 katlı filmin $(\mathrm{hv})^{2}-(\mathrm{hv})$ grafiği 
Amorf yapıdaki 7 katlı $\mathrm{TiO}_{2}$ filmler $\% 88$ gibi yüksek geçirgenliğe sahip olmalarına karşın kristal yapıdaki $\mathrm{TiO}_{2}$ filmler yaklaşık \%74 geçirgenliğe sahiptir. Soğurma verilerinden yararlanılarak çizilen $(\alpha h v)^{2}-(h v)$ grafiğinden filmin yasak enerji aralığı $3,82( \pm 0,02)$ eV olarak bulunmuştur. $\mathrm{Bu}$ sonuç, kaynaklarda yer alan değerlerle uyumludur [32].

$\mathrm{TiO}_{2}$ filmler, ITO taşıyıcılar üstüne tek katlı ve 3 katlı olarak kaplanmıştır. Kaplanan filmlerden bazıları sadece $120^{\circ} \mathrm{C}$ 'de kurutulmuş, bazıları ise $120^{\circ} \mathrm{C}$ 'de kurutulduktan sonra $500^{\circ} \mathrm{C}$ 'de 1 saat boyunca tavlanmıştır. ITO üstüne kaplanan ve $120^{\circ} \mathrm{C}$ 'de kurutulan tek ve 3 katlı $\mathrm{TiO}_{2}$ filmlerin XRD ölçümlerinden bu filmlerin amorf yapıda olduğu görülmüştür. $120^{\circ} \mathrm{C}$ 'de kurutulan $\mathrm{TiO}_{2}$ filmlerde herhangi bir tepe olmamasının sebebi, tavlama sıcaklığının kristalleşme için yeterli olmamasıdır. Bu durum $\mathrm{TiO}_{2}$ için beklenen bir sonuçtur.

$500^{\circ} \mathrm{C}^{\prime}$ de tavlanan tek katlı ve 3 katl $\mathrm{TiO}_{2}$ filmlerin XRD ölçümleri bu filmlerin kristal yapıda olduğunu göstermektedir (Şekil 6). Bu yapının, ICDD'nin 01-075-2547 kart numaralı $\mathrm{TiO}_{2}$ anataz yapısı ile uyumlu olduğu görülmüş̧ür. Oluşan tepeler (101), (103), (004), (112), (200), (105) ve (211)'dir. Grafikten 3 katlı filmlere ait tepelerin daha belirgin olduğu görülmektedir. Tepelerin tek katlı olarak kaplanan filmlere göre daha şiddetli ve keskin olması, filmin daha kalın ve daha iyi bir şekilde kristallenmiş olduğunun bir göstergesidir. Cam taşıyıcı üstüne 3 katlı olarak kaplanan $\mathrm{TiO}_{2}$ ince filmde tepe gözlenmemesine karşın ITO üstüne 3 katlı olarak kaplanan $\mathrm{TiO}_{2}$ ince filmde tepe gözlenmesi, kristallenmeyi zorlaştıran amorf taşıyıcı etkisinden kaynaklanmaktadır. XRD grafiğinden elde edilen veriler ve Scherrer Formülü ile hesaplanan kristal boyutları Tablo 3'de verilmiştir. Tek ve 3 katlı filmler için ortalama kristal boyutu yaklaşık olarak 15 nm'dir.

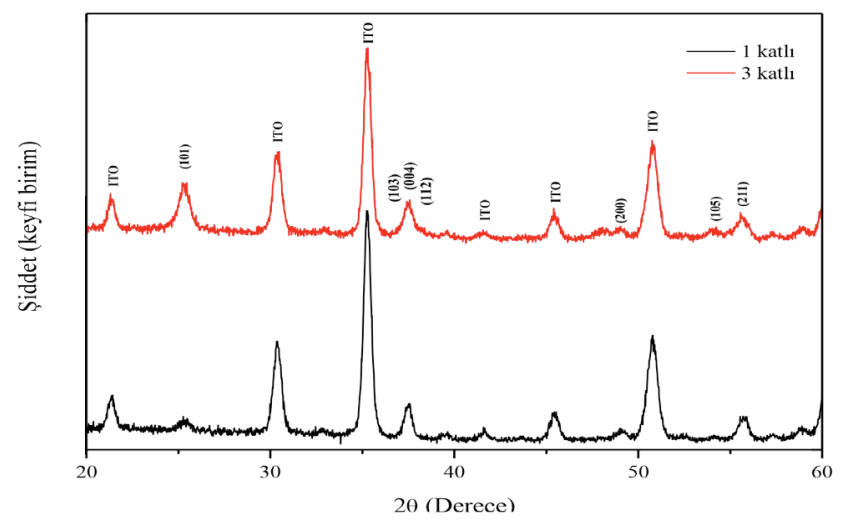

Şekil 6. ITO taşıyıcı üstüne kaplanmış ve $500^{\circ} \mathrm{C}$ 'de 1 saat tavlanmış tek ve 3 katlı filmlerin XRD grafiği
Tablo 3. ITO taşıyıcı üstüne kaplanmış ve $500^{\circ} \mathrm{C}$ 'de 1 saat tavlanmış tek ve 3 katlı $\mathrm{TiO}_{2}$ filmlerin XRD verileri

\begin{tabular}{cccccccc}
\hline \multirow{2}{*}{$\begin{array}{c}\text { Miller } \\
\text { indisleri } \\
\text { (hkl) }\end{array}$} & \multicolumn{2}{c}{ Tepenin olduğu } & \multicolumn{2}{c}{ FWHM } & \multicolumn{2}{c}{ Kristal } \\
& Tek & Üç & Tek & Üç & Tek & Üç \\
& Katl1 & Kat1ı & Katl1 & Katl1 & Katlı & Katl1 \\
\hline$(101)$ & 25,29 & 25,31 & 0,72 & 0,73 & 11,82 & 11,65 \\
$(004)$ & 37,46 & 37,52 & 0,48 & 0,57 & 18,26 & 15,38 \\
$(200)$ & 49,13 & 49,08 & 0,59 & 0,52 & 15,47 & 17,53 \\
$(211)$ & 55,68 & 55,59 & 0,58 & 0,62 & 16,18 & 15,13 \\
\hline
\end{tabular}

Filmlerin yüzey yapıları SEM fotoğrafları ile incelenmiştir. Şekil $7 \mathrm{a}$ ve $7 \mathrm{~b}$ 'de $120^{\circ} \mathrm{C}^{\prime}$ de 1 saat kurutulmuş tek ve 3 katlı filmlere ait SEM görüntüsü verilmektedir. Şekil 7c'de ise $120^{\circ} \mathrm{C}^{\prime}$ de 1 saat kurutulduktan sonra $500{ }^{\circ} \mathrm{C}^{\prime}$ de 1 saat tavlanan tek katlı filme ait SEM görüntüsü vardır. Her üç filmin yüzeyinin de düzgün olarak kaplandığı ve homojen dağılıma sahip olduğu görülmektedir.
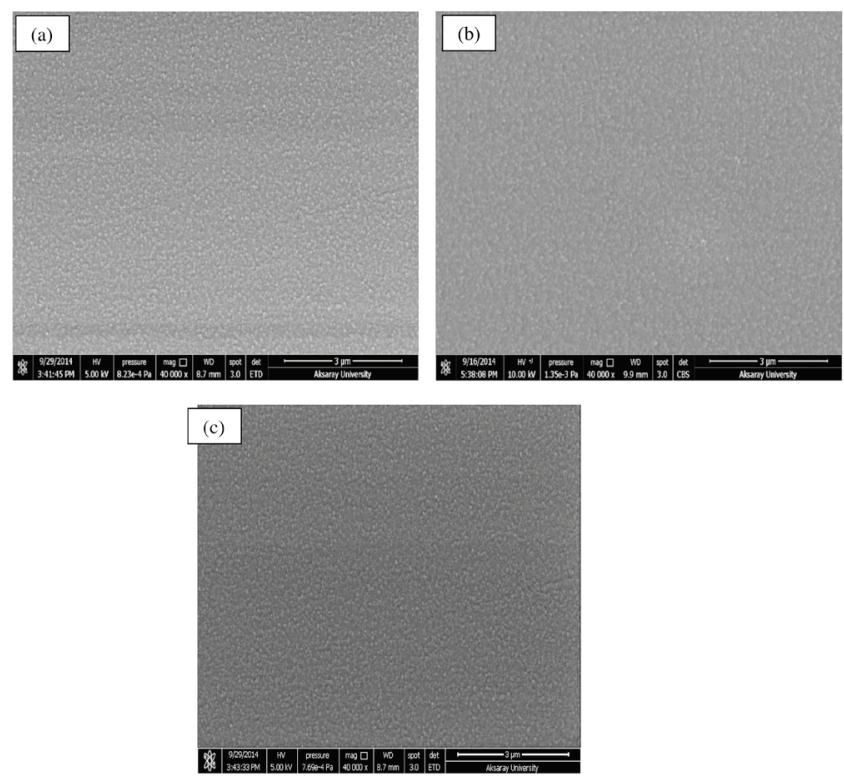

Şekil 7. $120{ }^{\circ} \mathrm{C}^{\prime}$ de 1 saat kurutulmuş (a) tek katlı filmin (b) 3 katlı filmin SEM görüntüsü, (c) $120{ }^{\circ} \mathrm{C}^{\prime}$ de 1 saat kurutulduktan sonra $500{ }^{\circ} \mathrm{C}$ ' de 1 saat tavlanan tek katl filmin SEM görüntüsü

\subsection{TiO2 Filmlerin Elektrokromik Özellikleri}

ITO taşıyıcı üstüne sol-jel döndürerek kaplama yöntemi ile kaplanan tek ve 3 katlı filmlerin elektrokimyasal ölçümleri için standart üç elektrotlu hücre kullanılmıştır. Bunun için 
$\mathrm{TiO}_{2} / \mathrm{ITO}$ çalışma elektrotu, platin tel karşıt elektrot olarak ve $\mathrm{Ag} / \mathrm{AgCl}$ de referans elektrot olarak seçilmiştir. Çalışma elektrotu olan $\mathrm{TiO}_{2}$ ince filmlerin elektrokimyasal ölçümleri, etanol içinde çözünmüş $1 \mathrm{M} \mathrm{KOH}$ elektroliti kullanılarak yapılmıştır. Filmlerin dayanma sınırını ve hangi bölgede renklendiklerini anlamak amaciyla $+1,5 \mathrm{~V}-(-1,5) \mathrm{V}$ aralığında ve $20 \mathrm{mV} / \mathrm{s}$ tarama hızında deneme ölçümleri yapılmıştır. Yapılan deneme ölçümleri sonucunda $(-0,8)$ $\mathrm{V}-(-1,45) \mathrm{V}$ aralığının uygun olduğu görülmüştür. $-1,45$ V'tan daha düşük değerlerde filmin bozulduğu gözlenmiştir. Genel olarak her numune $(-0,8) \mathrm{V}-(-1,45) \mathrm{V}$ aralığında 20 $\mathrm{mV} / \mathrm{s}$ tarama hızında 30 çevrim yapacak şekilde taranmış ve elde edilen veriler, filmin elektrolit içerisine daldırılan yüzey alanına bölünerek standartlaştırılmıştır.

Sol-jel döndürerek kaplama yöntemi kullanılarak hazırlanan filmlerin $120^{\circ} \mathrm{C}$ 'de 1 saat kurutma işlemine tabi tutulduktan sonra elektrokromik ölçümleri alınmıştır. Tek katlı ve 3 katlı filmlerin $1 \mathrm{M} \mathrm{KOH}$ içerisinde alınan Dönüşümlü Voltametri (Cyclic Voltammetry, CV) ölçüm sonuçlarından elde edilen verilere ait grafikleri Şekil 8'de görülmektedir.
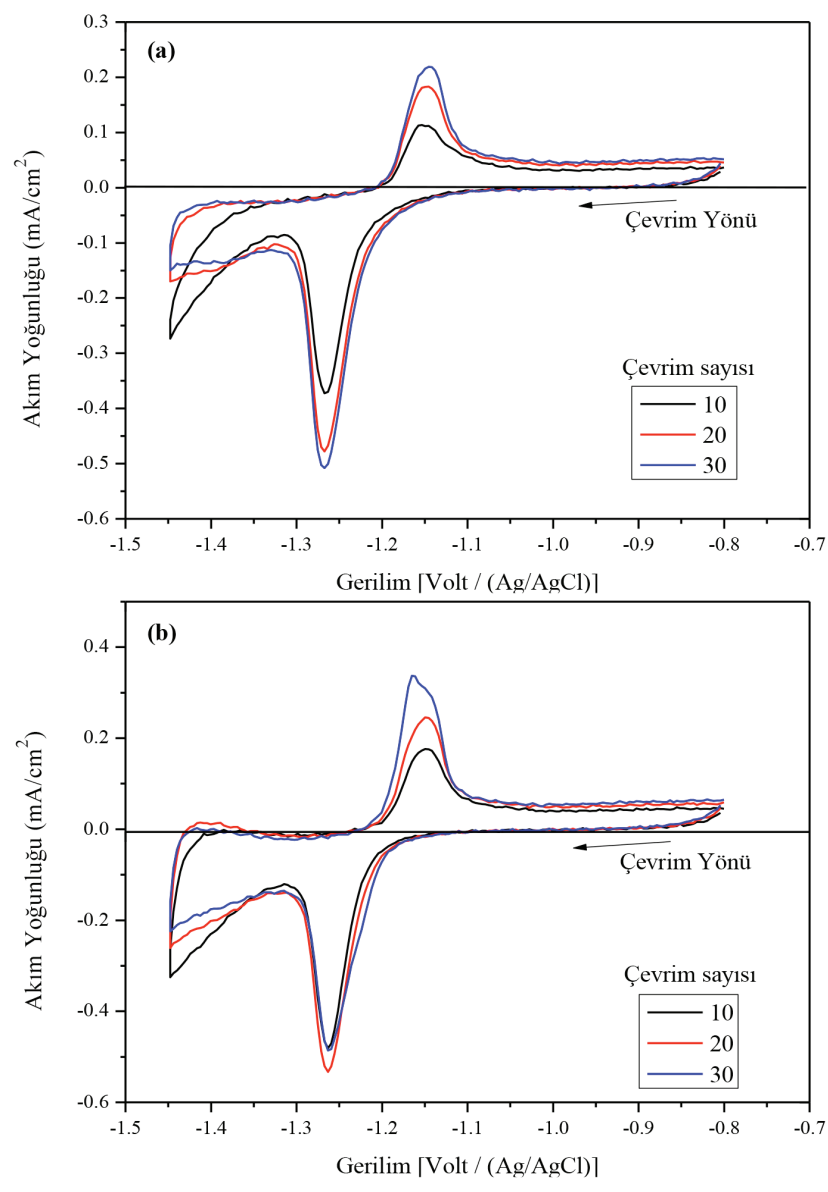

Şekil 8. (a) Tek katlı filmin, (b) 3 katlı filmin $1 \mathrm{M} \mathrm{KOH}$ içerisinde alınan CV ölçüm sonuçlarına ait grafikleri
Elektrokimyasal ölçüm sonuçlarından 10 . çevrimden 30 . çevrime kadar filmin iyon tutma kapasitesinin (filme giren iyon miktarı) arttı̆̆ 1 görülmüştür. $\mathrm{TiO}_{2}$ filmlerin içlerinde kalan yük miktarları;

$Q=Q_{\text {Katodik }}-Q_{\text {Anodik }}$

denklemi ile hesaplanmıştır. Bu denklemde $\mathrm{Q}_{\text {Katodik }} \mathrm{ve}_{\text {Anodik }}$ sırasıyla filme giren ve filmden çıkan yük miktarlarını göstermektedir. $\mathrm{Bu}$ denklem kullanılarak hesaplanan sonuçlar Tablo 4.'de gösterilmektedir.

Tablo 4. Tek katlı ve 3 katlı filmlerin $1 \mathrm{M} \mathrm{KOH}$ elektroliti içinde 20. çevrim sonundaki yük durumları

\begin{tabular}{cccccc}
\hline Giren yük $\left(\mathbf{m C} / \mathbf{c m}^{2}\right)$ & $\begin{array}{c}\text { Çıkan yük }(\mathbf{m C} / \\
\left.\mathbf{c m}^{2}\right)\end{array}$ & $\begin{array}{c}\text { Film içerisinde } \\
\text { kalan yük }(\mathbf{m C} / \\
\left.\mathbf{c m}^{2}\right)\end{array}$ \\
Tek Katlı Üç Katlı & $\begin{array}{c}\text { Tek } \\
\text { Katlı }\end{array}$ & $\begin{array}{c}\text { Üç Katlı } \\
\text { Katl }\end{array}$ & $\begin{array}{c}\text { Tek } \\
\text { Katlı }\end{array}$ & $\begin{array}{c}\text { Üç } \\
\text { Katl }\end{array}$ \\
\hline 2,98 & 2,83 & 1,11 & 1,46 & 1,87 & 1,37 \\
\hline
\end{tabular}

Filmlerde bir anodik tepe ve bir katodik tepe gözlenmiştir. Katodik tepe $-1,26$ V'ta oluşmuştur. Çevrim sayısı artıkça katodik tepeye karşılık gelen akım yoğunluğu da artmaktadır. Filmlere her çevrimde daha fazla $\mathrm{H}^{+}$girdiği, katodik tepenin şiddetinin artmasından ve eğriler arasında kalan alanın büyümesinden anlaşılmaktadır. 3 katlı filmlere giren yük miktarı tek katlı filmlere göre daha az olmuştur. Ancak çıkan yük miktarı tek katlı filmden daha fazladır. CV ölçümlerinde film içerisine giren yüklerin tamamının geri çıkması ideal durumdur. Dolayısıyla filmin içerisinde ne kadar az yük kalırsa çevrimin tekrar edilebilirliği ve filmin kalitesi o kadar fazla olur. Tablo 4.'de görüldüğü gibi 3 katlı film içeresinde kalan yük miktarı tek katlı filmlere göre daha azdir.

$\mathrm{TiO}_{2}$ filmler kaplandığ 1 anda şeffaf iken; $1 \mathrm{M} \mathrm{Ag} / \mathrm{AgCl}$ elektrotu ve $1 \mathrm{M} \mathrm{KOH}$ elektroliti kullanılarak CV ölçümü yapıldığında filmler koyu gri rengini almaktadır. Şekil 9'da; CV ölçümü yapılmış $\mathrm{TiO}_{2}$ filmler beyaz bir zemin üzerinde görülmektedir. 


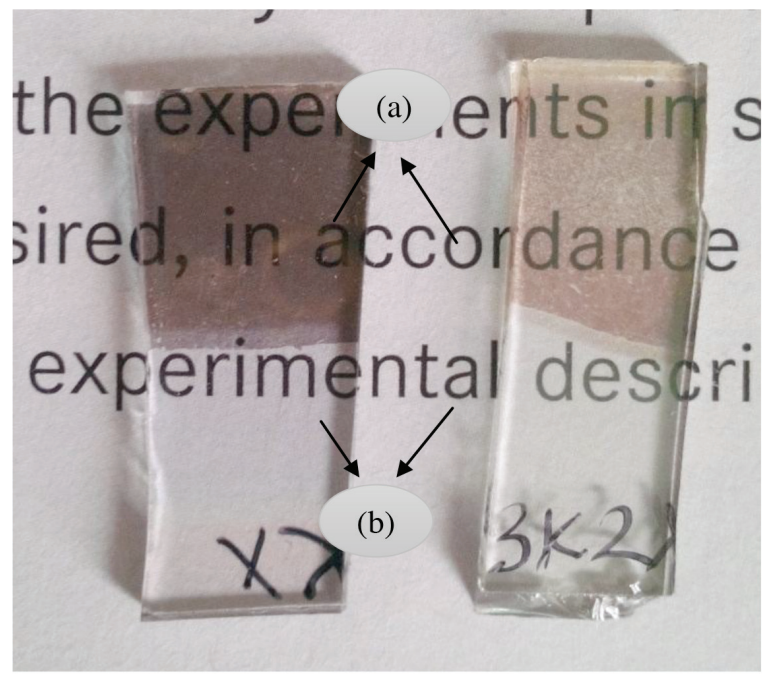

Şekil 9. Elektrokromik ölçümü yapılmış $\mathrm{TiO}_{2}$ ince filmler (a) Ölçüm için sıvıya daldırılan kısım (b) sıvıya daldırılmayan k1sim

\section{SONUÇLAR}

$\mathrm{Bu}$ çalışmada titanyum (IV) bütoksit, etanol, asetik asit başlangıç malzemeleri kullanılarak saf $\mathrm{TiO}_{2}$ ince filmler üretilmiştir. Film kaplamak için sol-jel döndürerek kaplama yöntemi kullanılmış ve 2000 devir/dakika döndürme hızında 1 dakika boyunca kaplama işlemi gerçekleştirilmiştir. Filmler, ITO ve Corning 2947 cam taşıyıcılar üstüne çeşitli katman sayılarına sahip olacak şekilde hazırlanmışlardır.

Yapılan XRD ölçümlerine göre, cam taşıyıcılar üstüne kaplanan ve sadece $500{ }^{\circ} \mathrm{C}$ ' de 1 saat tavlanmış 7 katlı filmlerde tepe görülmüştür. Filmler anataz yapıda olup ortalama kristal boyutu yaklaşık $17 \mathrm{~nm}$ 'dir. ITO üstünde yapılan kaplamaların XRD sonuçları incelendiğinde $500{ }^{\circ} \mathrm{C}$ ' de tavlanmış 1 katlı ve 3 katlı filmlerin de anataz yapıya sahip oldukları görülmüştür. Ayrıca 3 katlı filmlerin XRD tepelerinin şiddetinin 1 katlı filmlere göre daha fazla olduğu gözlenmiştir. $\mathrm{Bu}$ şiddet farkının (101) düzleminde daha belirgin olduğu bulunmuştur. Tek katlı ve 3 katlı filmlerin ortalama kristal boyutu $15 \mathrm{~nm}$ civarındadır. Filmlerin SEM görüntüleri incelendiğinde filmlerin yüzeyinin düzgün olarak kaplandığı ve homojen yapıya sahip oldukları gözlenmiştir.

Cam taşıyıcılar üstüne kaplanmış $\mathrm{TiO}_{2}$ filmlerin geçirgenlik grafikleri incelendiğinde filmlerin katman sayısı artıkça grafiklerdeki tepe ve çukur sayısının da arttığı gözlenmiştir. $\mathrm{Bu}$ da kalınlığı artan filmler için beklenen bir sonuçtur. Hazırlanan $\mathrm{TiO}_{2}$ filmler genel olarak yüksek geçirgenliğe sahiptir. Filmlerin geçirgenliğinin isıl işlemin etkisiyle azaldığı, geçirgenlik grafiklerinde yer alan tepe ve çukurların kaydığı tespit edilmiştir. Yapılan 1 sıl işlem sonucunda 650 $\mathrm{nm}$ civarında elde edilen maksimum geçirgenliğin 7 katlı filmler için \%83'ten \%62'ye düştüğü görülmüştür.

Amorf filmlerin yasak enerji aralığının 3,78 eV ile 4,04 eV arasında değiştiği görülmüştür. Filmlerde katman sayısı artıkça filmlerin yasak enerji aralığının azaldığı gözlenmiştir. Anataz yapıya sahip 7 katlı filmin yasak enerji aralığ 3,82 eV olarak hesaplanmıştır.

Filmlerin elektrokimyasal özelliklerini incelemek için $1 \mathrm{M}$ $\mathrm{KOH}$ elektroliti, karşıt elektrot olarak platin tel, referans elektrot olarak $1 \mathrm{M} \mathrm{Ag/AgCl}$ elektrot ve çalışma elektrotu olarak $\mathrm{TiO}_{2}$ filmler kullanılmıştır. $20 \mathrm{mV} / \mathrm{s}$ tarama hızında alınan ölçüm sonuçlarına göre $\mathrm{TiO}_{2}$ filmlerin elektrokromik özellik gösterdiği gözlenmiştir. İyon giriş çıkışı açısından 3 katlı olarak hazırlanan filmin tek katlı filme göre daha verimli olduğu bulunmuştur. Filmlerde test edildikleri 30 çevrim sonunda herhangi bir bozulma görülmemiştir. Soljel yöntemiyle elde edilen $\mathrm{TiO}_{2}$ amorf filmlerin katodik elektrokromik özellik göstererek renginin hızlı bir şekilde şeffaftan koyu griye döndüğü gözlenmiştir.

\section{TEŞEKKÜR}

$\mathrm{Bu}$ çalışma, birinci yazar tarafindan Mustafa Kemal Üniversitesi Fen Bilimleri Enstitüsü, Fizik Anabilim Dalı'nda tamamlanmış olan "Sol-Jel Yöntemiyle Hazırlanan TiO2 Filmlerin Elektrokromik Özellikleri” adlı yüksek lisans tezinden üretilmiş olup; MKU Bilimsel Araştırma Projeleri Kurum Koordinatörlüğü (Proje No: 10260) tarafından desteklenmiştir.

\section{KAYNAKLAR}

[1] Granqvist, C.G.(1995). Handbook of inorganic electrochromic materials, Elsevier, Amsterdam, The Netherlands

[2] Granqvist, C.G. (2000). Electrochromic tungsten oxide films: Review of progress 1993-1998, Solar Energy Materials and Solar Cells., 60, 201-262.

[3] Superamerica, http://auto.ferrari.com/en_US/sports-carsmodels/pastmodels/superamerica/(Erişim tarihi: Mayıs 2016)

[4] Electrochromic windows, http://www.commercialwindows. org/ electrochromic.php (Erişim tarihi: Mayıs 2016)

[5] Lampert, C.M. (1998). Smart switchable glazing for solar energy and daylight control. Sol. Energy. Mat. Sol.Cells, 52, 207.

[6] Ma, C. , Taya, M., Xu, C.Y. (2008). Smart sunglasses based on electrochromic polymers. Polym. Eng. Sci., 48, 2224. [7] Leftheriotis, G., Syrrokastas, G., Yianoulis, P. (2010). Development of photoelectrochromic devices for dynamic solar control in buildings. Sol. Energy Mat. Sol. C., 94, 2313

[8] Dinh, N.N., Oanh, N.Th.T., Long, P.D., Bernard, M.C., Hugot-Le Goff, A. (2003). Electrochromic properties of TiO2 
anatase thin films prepared by a dipping sol-gel method. Thin Solid Films, 423,70[9]

[9] Tatsuo, N., Osamu, T., (2010). Optical and electrochemical properties of all-solid-state transmittance-type electrochromic devices. Thin Solid Films, 518,1727

[10] Karunagaran, B., Cchung, S.J., Suh, E.K., Mangalara, J. (2005). Dielectric and transport properties of magnetron sputtered titanium dioxide thin films. Physica, B, 369, 129-134.

[11] Leprince-Whang, Y., Yu-Zhang, K. (2001). Study of the growth morphology of TiO2 thin films by AFM and TEM. Surf. and Coat. Tech., 140, 155-160.

[12] Walid, A.D., John, H.X., Yi-He, Z., Kaihong, Q. (2005). Surface characterization of titania films prepared at low temperatures. Journal of Non-Crystalline Solids, 351, 1486-1490.

[13] Helsch, G., Deubener., J. (2012). Compatibility of antireflective coatings on glass for solar applications with photocatalytic properties. Sol. Energy, 86, 831-836.

[14] Liu, Z., Zhang, X., Murakami, T., Fujishima, A. (2008). Sol-gel $\mathrm{SiO} 2 / \mathrm{TiO} 2$ bilayer films with self-cleaning and antireflection properties. Sol. Energy, Mater. Sol. C., 92, 1434-1438.

[15] Gondek, E., Karasinski, P., (2013). High reflectance materials for photovoltaics applications: analysis and modelling. J. Mater. Sci., Mater. Electron., 24(8), 2934-2943.

[16] Hitosugi, T., Yamada, N., Nakao, S., Hirose, Y., Hasegawa, T. (2010). Properties of TiO2- based transparent conducting oxides. Phys. Status Solidi A, 207(7), 1529-1537.

[17] Gondek, E., Djaoued, Y., Robichaud, J., Karasinski, P., Kityk, I.V., Danel, A., Plucinski, K.J. (2012). Influence of TiO2 nanoparticles on the photovoltaic efficiency of the ITO/ PEDOT:PSS/fluorine copolymers/polythiphene:TiO2/Al architecture. Mater. Electron, 23, 2057-2064.

[18] Senthil, T.S., Muthukumarasamy, N., Thambidurai, M., Balasundaraprabhu, R., Agilan, S. (2011). Light conversion efficiency of flower like structure $\mathrm{TiO} 2$ thin film solar cells. J. Sol-Gel Sci. Technol, 58, 296-301.

[19] Bardakçı, S. (2007). Sol-jel yöntemi ile hazirlanan TiO2 ince filmlerinin optik özelliklerinin belirlenmesi. Yüksek Lisans Tezi, Sakarya Üniversitesi.

[20] Hasan, M.M., A.S.M.A. Haseeb, R. Saidur, H.H. Masjuki, M. Hamdi. (2010). Influence of substrate and annealing temperatures on optical properties of RF-sputtered $\mathrm{TiO} 2$ thin films. Opt. Mater, 32 (6) 690-695.
[21] Blesic, M.Dj., Saponjic, Z.V., Nedeljkovic, J.M., Uskokovic, D.P. (2002). TiO2 films prepared by ultrasonic spray pyrolysis of nanosize precursor. Mat. Lett., 54, 298-302.

[22] Jung, S-Ch., Kim, B-H., Kim, S-J., Imaishi, N., Cho, Y-I. (2005). Characterization of a $\mathrm{TiO} 2$ photocatalyst film deposited by CVD and its photocatalytic activity. Chem. Vap. Depos, 11(3), 137141.

[23] Lin, H., Rumaiz, A. K., Schulz, M., Wang, D., Rock, R., Huang, C.P., Shah, S.I. (2008). Photocatalytic activity of pulsed laser deposited TiO2 thin films. Mater. Sci. Eng. B-Solid., 151, 133139.

[24] Sorar, İ., Pehlivan, E., Niklasson, G. A., Granqvist, C. G.. (2013). Electrochromism of DC magnetron sputtered TiO2 thin films: role of deposition parameters. Solar Energy Materials and Solar Cells, 115,172-180.

[25] Gondek, E., Karasin' ski, P., Drewniak, S., (2014). Nanoquantum size effect in sol-gel derived mesoporous titania layers deposited on soda-lime glass substrate. Phys. E, Low-Dimens. Syst. Nanostruct., 62, 128-135.

[26] Başar Yüncü, F. S. (2012). Sol-jel yöntemiyle katkısız ve boya katk1lı TiO2 ince filmlerin hazırlanması ve karakterizasyonu. SDÜ Fen Bilimleri Enstitüsü Yüksek Lisans Tezi.

[27] Özbey, P.E. (2004). Sol-gel yöntemiyle hazırlanan SiO2-TiO2 esaslı yansıtmayıcı kaplamalar. Yüksek Lisans Tezi, İstanbul Teknik Üniversitesi.

[28] Niu, W., Wang, G., Liu, X., Tang, J., Xiao-guoBi. (2015). Preparation and Electrochromic Performance of TiO2 thin film. Int. J. Electrochem. Sci., 10, 2613 - 2620

[29] Hosseini, A., Icli, K. C., Güllü, H. H. (2013). Preparation and characterization of porous $\mathrm{TiO} 2$ thin films by sol-gel method for extremely thin absorber-ETA solar cell applications. Turkish Journal of Science \& Technology, 8(2), 69-79.

[30] Ganjoo, A., Golovchak, R. (2008). Computer program PARAV for calculating optical constants of thin films and bulk materials: Case study of amorphous semiconductors. Journal of Optoelectronics and Advanced Materials, 10(6), 1328-1332.

[31] Wood, D.L., Tauc, L. (1972). Weak absorption tails in amorphous semiconductors. Physical Review B, 5 (8), 3144-3151.

[32] Verma, A., Kar, M., Agnihotry, S. A. (2007). Aging effect of diethanolamine stabilized sol on different properties of $\mathrm{TiO} 2$ films: electrochromic applications. Solar Energy Materials and Solar Cells, 91, 1305-1312. 